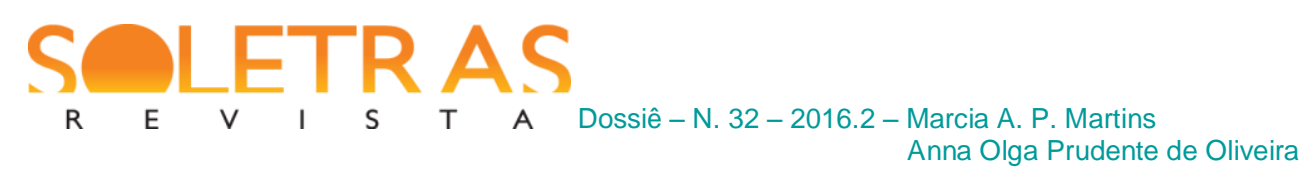

\title{
Alice e $O$ mestre ignorante: relações entre a obra literária e a experiência educacional ${ }^{i}$
}

\author{
Marcia A. P. Martins ${ }^{1}$ \\ Anna Olga Prudente de Oliveira ${ }^{2}$ \\ Pontifícia Universidade Católica do Rio de Janeiro (PUC-Rio)
}

\begin{abstract}
Resumo: Este artigo propõe uma análise da obra Aventuras de Alice no país das maravilhas de Lewis Carroll, com base na leitura de $O$ mestre ignorante de Jacques Rancière (2013) (Le maître ignorant, 1987). Considerando que Alice pertence ao cânone da literatura infantojuvenil, busca-se apontar aspectos na escrita de Carroll que distanciam a obra de uma literatura infantojuvenil de cunho educativo e/ou moralizante. Sem uma narrativa linear, Carroll traz para sua escrita a dimensão infantil, priorizando uma experimentação da própria linguagem. Essa experimentação e a escrita literária elaboradas sem um caráter teleológico, sem o intuito aparente de um ensinamento, são aspectos que possibilitam uma analogia com o texto de Rancière, no qual o autor, rompendo com a tradicional hierarquia na relação mestrealuno, apresenta uma proposta radical de emancipação intelectual. Neste percurso de articulação da escrita literária de Carroll com as "lições de emancipação intelectual" de Rancière, são discutidos caminhos tomados em duas reescritas brasileiras de Alice, a de Jorge Furtado e Liziane Kugland (2008) e a de Maria Luiza Borges (2013).
\end{abstract}

Palavras-chave: Literatura infantojuvenil. Tradução e adaptação. Emancipação intelectual. Lewis Carroll. Jacques Rancière.

\section{A alteridade da infância nos leva a uma região em que não comandam as medidas do nosso saber e do nosso poder.}

JORGE LARROSA

\section{Alice Liddell: a dimensão do desejo na literatura}

A obra Alice's Adventures in Wonderland de Lewis Carroll pertence ao cânone da literatura infantojuvenil (LIJ), sendo lida por diversas gerações em várias partes do mundo, desde sua publicação em 1865. Carroll, pseudônimo de Charles Lutwidge Dodgson, escreveu

\footnotetext{
${ }^{1}$ Marcia A. P. Martins é doutora em Comunicação e Semiótica pela PUC-SP, tendo realizado estágio pósdoutoral na Queen Mary University of London em 2012. Tradutora e professora, atua nos cursos de formação de tradutores e no Programa de Pós-Graduação em Estudos da Linguagem da PUC-Rio. Seus interesses de pesquisa incluem a historiografia da tradução e reescritas de clássicos da literatura. E-mail: martins @ domain.com.br

2 Anna Olga Prudente de Oliveira é doutoranda em Estudos da Linguagem na PUC-Rio, mestre em Estudos da Linguagem e Bacharel em Letras - Tradutor (inglês-português) pela mesma instituição. Tradutora e pesquisadora na área de Estudos da Tradução, é também Bacharel em Artes Cênicas pela UNI-Rio. Integra o corpo editorial da revista Escrita (PUC-Rio) e tem atuado como parecerista ad hoc da revista Versalete (UFPR). E-mail: annaolga@terra.com.br
} 
a história para sua amiga, a pequena Alice Liddell, de apenas 10 anos, uma das crianças que mais o estimulava a contar histórias. Em um artigo, anos mais tarde, o autor comenta o momento de criação da obra que o tornaria tão célebre:

numa tentativa desesperada de chegar a um conto de fadas de feição diferente, eu, para começar, tinha despachado minha heroína diretamente por uma toca de coelho, sem a mínima ideia do que deveria acontecer depois. E assim, para agradar a uma criança que eu amava (não me lembro de nenhum outro motivo), escrevi a mão e ilustrei com meus próprios desenhos toscos ${ }^{3}[\ldots] \mathrm{o}$ livro que acabo de publicar. (Carroll, 2013, p.256)

Considerando a época de Lewis Carroll, a Inglaterra vitoriana da segunda metade do século XIX, neste trabalho discutimos o modo singular com que o autor convoca a infância na elaboração de sua escrita literária e buscamos realizar uma articulação de sua obra com o conceito de emancipação intelectual apresentado por Jacques Rancière em $O$ mestre ignorante. A experimentação e a escrita literária de Carroll elaboradas sem o intuito aparente de um ensinamento são aspectos que possibilitam uma analogia com o texto de Rancière, no qual o autor, rompendo com a tradicional hierarquia na relação mestre-aluno, apresenta uma proposta radical de emancipação intelectual, como veremos. E, ainda, através da apresentação de duas reescritas brasileiras contemporâneas de Alice, abordamos modos possíveis de lidar com tal escrita literária em outra época e cultura. Se a obra surge a partir do pedido de uma criança, sendo a própria transformada em personagem central, veremos no entanto que a história não está comprometida com o caráter didático tão comum a histórias voltadas para o público infantojuvenil. Como são os adultos a escrever as histórias para as crianças,

a primeira peculiaridade da LIJ surge [...] a partir da relação desigual entre autor e seu público preferencial, uma vez que o adulto é o responsável por definir as obras que serão escritas (ou reescritas) e publicadas para as crianças, sendo ele portanto quem tem o poder de decidir sobre aquilo que é ou não apropriado a tal público. (Oliveira, 2014, p.30)

Nesse sentido, a LIJ tradicionalmente é um tipo de literatura que pressupõe uma intencionalidade por parte daquele que a escreve, visando muitas vezes a educação das crianças. Com efeito, o desenvolvimento da LIJ enquanto gênero vincula-se ao "entendimento de criança como um ser cuja natureza distinta precisava ser moldada e desenvolvida espiritualmente", em detrimento da concepção de criança como "adulto em miniatura"

\footnotetext{
${ }^{3}$ Escrita a mão e ilustrada pelo próprio autor, a primeira versão de Alice intitulava-se Alice's Adventures Under Ground. Em 1865, a obra foi publicada como Alice's Adventures in Wonderland com ilustrações de John Tenniel.
} 
prevalecente até o século XVI, a qual não distinguia necessidades e interesses distintos entre “crianças" e "adultos" (Oliveira, 2014, p.36). Como aponta Zohar Shavit,

até o século XVII a criança não era vista como uma entidade distinta do adulto, e consequentemente não era reconhecida por suas necessidades especiais. Um dos resultados dessa perspectiva era a ausência de um sistema educacional estabelecido para crianças, e de livros escritos especialmente para elas ${ }^{4}$. (Shavit, 1999, p. 318)

Tendo surgido sob a perspectiva educacional, a LIJ é desde seus primórdios marcada sobretudo por um caráter didático, tendo como uma de suas funções mais preponderantes a transmissão de valores e conhecimentos. Tal característica, muitas vezes moralizante, vem sendo ao longo do tempo modificada ou atenuada à medida que o gênero se desenvolve, se distanciando de textos didáticos, com seu caráter propriamente literário passando a exercer papel central. Ao se tornar autônoma como sistema literário, a LIJ pode dançar a verdade colocando em cena os jogos de linguagem, o lúdico e a poesia. Se atualmente os autores de LIJ já podem, com maior facilidade, afastar-se de um didatismo moralizante, a publicação de obras para crianças no século XIX, no Brasil, por exemplo, vinculava-se ainda a um projeto "de guiar as crianças no caminho do bem e da virtude" (Pimentel, 1911, catálogo, p.11), como anunciado pelos editores de Contos da Carochinha, coletânea de contos populares elaborada por Figueiredo Pimentel e publicada pela primeira vez em 1894. Obra de grande sucesso, Contos da Carochinha se apresentava com um propósito educativo, buscando instruir e transmitir valores. Havia desse modo uma clara relação hierárquica entre autor e leitor, na qual o autor, com base em seu amplo conhecimento de mundo, restringia os temas e a linguagem de sua obra literária para torná-la adequada às limitações de conhecimento das crianças, bem como a determinados valores considerados apropriados para serem transmitidos. Essa função moralizante da literatura marca também a Inglaterra do século XIX, período em que se desenvolve um tipo de literatura pedagógica como, por exemplo, a de Margaret Gatty, que publica, em 1855, Parables from nature, primeira de cinco séries que buscavam mostrar a necessidade de manutenção da ordem social, "tarefa que somente o enraizamento dos valores morais poderia concluir [...]. Havia a intenção de se ensinar que a submissão é algo natural e bom" (Morais, 2004, p.69).

Diferentemente dessa literatura moralizante do século XIX, a Alice de Carroll, tão marcada por uma dimensão afetiva em que o desejo gera a escrita, não se doma facilmente a

\footnotetext{
${ }^{4}$ Tradução nossa.
} 
definições convencionais que classificam uma obra para criança ou para adulto. Alice pode ser considerada uma obra ambivalente, como propõe Shavit, podendo ser lida por crianças e jovens, mas também podendo ser apreciada por adultos em uma leitura mais sofisticada (Shavit, $1986^{5}$ apud O’Connell, 2006, p.17). E talvez não seja mesmo o caso de pensar de modo stricto sensu que se trate de uma obra para criança, mas sim, como sugere Virginia Woolf, que Carroll convida o leitor a tornar-se criança (Carroll, 2012, p. 246), a experimentar sensações, angústias, de quem não tem o controle, nem as respostas, e que está portanto aberto ao devir. Alice, ao contrário de muitas histórias para crianças, como por exemplo os contos de fadas tradicionais, não apresenta uma narrativa que se desenvolva linearmente com o início, o conflito (ou complicação) e o fim, no qual há um desenlace ou final feliz. Na obra, temos uma junção de episódios que se ligam não pelo "conteúdo" daquilo que acontece, mas muito mais pela "forma", literalmente por transformações físicas da personagem - as passagens de uma cena à outra são marcadas pelo aumento ou diminuição repentinos de Alice.

Os acontecimentos de Alice relacionam-se quase sempre a uma experimentação que se dá no nível da linguagem; o dizer torna-se fazer. As possibilidades de expressão linguística são exploradas, torcendo e esgarçando o que seria um sentido forjado a priori. Carroll explora uma língua em devir, uma ideia que remete a outra, uma palavra que cria uma realidade. A dimensão infantil, em que as palavras não remetem às coisas e não se encontram em sintaxe coerente, desequilibra a língua, fazendo-a "bifurcar e variar em cada um de seus termos, segundo uma incessante modulação" (Deleuze, 2011, p.124). Uma língua trôpega, cujos significantes geram o texto, esse "sonho de primavera que à teia da memória se entretece" (Carroll, 2013, p.8). Nada mais distante de uma literatura que pretenda transmitir uma mensagem, ensinar algo a partir de uma relação desigual entre aquele que detém o conhecimento - o autor - e o leitor-criança. Ainda que seja vista como uma obra escrita para criança, não é possível vislumbrar um olhar de superioridade intelectual do autor sobre a criança, não há aparentemente uma proposta educativa nos moldes tradicionais; o que vemos é uma experimentação da própria linguagem, ressaltando-se o sentido estético das palavras (sua própria materialidade), as quais se tornam significativas não por expressarem determinados significados, mas por serem expostas como objetos em si, objetos que se transformam, se embaralham, derretem em nossas mãos, mudam de lugar e adquirem novos

\footnotetext{
${ }^{5}$ Shavit, Zohar. Poetics of Children's Literature. Athens: University of Georgia Press, 1986. p.63-91.
} 
significados ao serem ditos - significados estes instáveis ou provisórios, pois, em Carroll, como diz Deleuze, "mesmo as palavras se comem" (Deleuze, 2011, p.31).

A experimentação da linguagem e a escrita literária elaboradas sem um caráter teleológico, sem o intuito de um ensinamento, são aspectos que possibilitam uma analogia de Alice com $O$ mestre ignorante de Jacques Rancière (2013). Assim como a LIJ teve tradicionalmente um comprometimento com o ensinar os (bons) caminhos às crianças, a tarefa do professor ou mestre explicador, como criticamente nos apresenta Rancière, é a de conduzir o aluno, ignorante, ao lugar do saber, é fornecer a esse ser inferiorizado determinado conhecimento.

\section{O mestre ignorante: uma metáfora para a vida}

Em $O$ mestre ignorante, Rancière reconta a aventura intelectual de Joseph Jacotot, filósofo e professor francês do século XIX que, ao assumir uma cátedra na Universidade de Louvain, em 1818, se depara com alunos que não podiam compreendê-lo, pois não falavam francês. O mestre tampouco falava holandês. Diante do impasse, buscando um elo para unir os dois polos apartados, Jacotot encontra uma edição bilíngue da obra As aventuras de Telêmaco do escritor francês Fénelon ${ }^{6}$. No entanto, o que o mestre propõe aos alunos é bastante inusitado: que eles aprendam o francês sem qualquer intervenção ou explicação de alguém que lhes ensine a gramática; que descubram sozinhos a língua francesa a partir da leitura... Poderiam aprender algo dessa forma, abandonados a si mesmos? Para a própria surpresa de Jacotot, os alunos embarcam nessa aventura e acabam se saindo muito melhor do que o esperado. Não só isso, mas as aulas de Jacotot passam a ser as mais disputadas, e o mestre amplia sua proposta emancipatória e passa a ministrar disciplinas distintas, sobre as quais não tem grande conhecimento ou domínio.

A experiência simboliza a proposta filosófica de Jacotot, que toma a igualdade como um princípio, não sendo portanto um objetivo a ser alcançado ao final de um projeto educativo. Enquanto a educação tradicional é calcada na relação entre um mestre explicador,

\footnotetext{
${ }^{6}$ No artigo Fénelon entre Antigos e Modernos, Tarsilla Couto de Brito comenta que Telêmaco foi um dos maiores best-sellers dos séculos XVIII e XIX, e que, segundo Albert Cherel, "foi o livro mais impresso, comentado, imitado e traduzido na Europa e fora dela durante o século XVIII. O sucesso editorial de Telêmaco perdura até a primeira metade do século XIX, quando passa a fazer parte dos programas escolares como texto insubstituível". Letras, Santa Maria, v.21, n.43, p.285-304, jul./dez.2011. https://www.yumpu.com/pt/document/view/13532707/fenelon-entre-antigos-e-modernos-tarsilla-ufsm/7
} 
que sabe determinado conteúdo e tem como tarefa ensiná-lo ao aluno ignorante, Jacotot considera ser necessário justamente abolir a distância existente na relação hierárquica mestrealuno, para que possa haver uma emancipação intelectual, a qual se dá pela vontade própria do aluno, e não pelo direcionamento ou orientação do professor. A lógica do sistema explicador, segundo ele, gera apenas um embrutecimento, uma vez que um fica sempre na dependência do outro; o mestre explicador precisa do ignorante para transmitir o seu saber, e o ignorante fica sempre à espera da explicação, daquele que irá lhe abrir as portas para o conhecimento, tornando-se assim incapaz de buscar por si mesmo conhecer o que deseja. Subjacente à lógica desse sistema está a necessidade de o mestre explicar a um aluno aquilo que se encontra em um livro. Ora, se o livro é constituído por um conjunto de raciocínios sobre determinada matéria, porque o leitor precisaria de um mestre que lhe explique aquilo que ele lê? O mestre explicador é aquele que dá uma palavra final fazendo "um conjunto de raciocínios para explicar o conjunto de raciocínios em que o livro se constitui. Mas por que teria o livro necessidade de tal assistência?” (Rancière, 2013, p.21).

Para Jacotot, essa lógica mantém a distância entre aqueles que detêm o saber e os que passivamente são conduzidos até certo ponto do conhecimento. Em sua proposta anarquista (no sentido de liberdade e responsabilidade individuais), como observa Walter Kohan, encontra-se a ideia de que "os alunos aprendem seguindo seus próprios métodos, através de caminhos que eles mesmos decidem" (Kohan, 2007, p.43). Ao mestre resta apenas uma tarefa de instigar o aluno, conduzindo-o sem amarras e sem direcionamento, abrindo-lhe perspectivas a partir de perguntas tais como, o que você vê? o que pensa disso? o que você faz com isso? Aí reside a ideia de mestre ignorante, um mestre que não é necessariamente um professor e que tampouco necessita saber o que ensina, mas que exerce o princípio da igualdade das inteligências.

O questionamento de Jacotot desestabiliza as bases da estrutura em que a educação é calcada. Como observa Kohan, "a explicação, tão criticada por Jacotot, é a chave-mestra do dispositivo pedagógico" (Kohan, 2007, p.40). O caráter teleológico da educação é visto como paradoxal pelo mestre ignorante: o processo educativo, que busca fazer com que todos se tornem iguais, com o acesso ao conhecimento, acaba perpetuando a desigualdade. Invertendo essa perspectiva, a proposta de Jacotot pressupõe que não há uma hierarquia da capacidade intelectual, mas sim que o aprendizado depende da vontade que se tem para

descobrir e combinar relações novas [...]. É a tomada de consciência dessa igualdade de natureza que se chama emancipação, e que abre o caminho para 
toda aventura no país do saber. Pois se trata de ousar se aventurar, e não de aprender mais ou menos bem, ou mais ou menos rápido. (Rancière, 2013, p.49)

Poderíamos dizer que, em Jacotot, "o mestre não é quem sempre ensina, mas quem de repente aprende" (Rosa, 1994, p.199); aprende nessa relação com o outro, que o surpreende, com a experiência da emancipação intelectual do outro.

Considerando o teor didático e moralizante da LIJ característico da época de Lewis Carroll, buscamos analisar essa experimentação da linguagem feita em sua obra, a qual se distancia de um projeto educativo infantil, como encontrado, por exemplo, nos contos de fadas tradicionais, nos quais temos um aprendizado ou uma lição ao final da narrativa, conforme já mencionado. A partir da leitura de $O$ mestre ignorante, seria possível pensar em Carroll como um escritor que emancipa a criança ao não lhe fornecer um caminho previsível e educativo? Em sua experimentação com a língua, com as sensações, com o devir corporal, enfim, com a dimensão infantil do não saber (qual caminho seguir, onde darão as portas...) e do continuar sem respostas, a escrita de Carroll poderia ser vista como indo em um sentido oposto ao do pensamento dominante do mestre explicador, o qual tem por princípio a inferioridade intelectual das crianças? (Rancière, 2013, p.49). Contrariamente aos explicadores que têm a "consciência de sua superioridade" (p.42), Carroll apresenta uma obra aberta, cujo objetivo não parece ser o de veicular conteúdos ou mensagens, mas o de descobrir na própria escrita a potência da língua. Como aponta Rancière,

a virtude de nossa inteligência está menos em saber, do que em fazer. 'Saber não é nada, fazer é tudo'. Mas esse fazer é fundamentalmente, ato de comunicação. E, portanto, 'falar é a melhor prova da capacidade de fazer o que quer que seja'. No ato de palavra, o homem não transmite seu saber, ele poetiza, traduz e convida os outros a fazer a mesma coisa. (p.96)

Tanto a proposta de Jacotot quanto a de Carroll não são modelos de verdade, apresentam-se como possibilidades, um modo de vida ou de escrita literária. Muito pertinente a ponderação de Walter Kohan a esse respeito:

Um livro tão belamente escrito, como $O$ mestre ignorante, convida a uma relação de experiência, a se situar no pensamento de uma maneira desestabilizante e problemática. Se, em troca, se lê $O$ mestre ignorante como um livro-verdade, não se tirará dele grande proveito, além de colocá-lo no lugar de sua morte, lugar que ele parece combater do início ao fim. Ao contrário, como experiência de leitura, Jacotot e Rancière podem ajudar-nos a não mais conseguir pensar do mesmo modo as questões que são tratadas. (Kohan, 2007, p. 47) 
Podemos dizer o mesmo sobre Alice e Carroll, que abrem as gavetas da infância adentrando um mundo em que nada é realmente impossível.

Se a ideia de emancipação intelectual dos indivíduos não se constitui como possível modelo hegemônico uma vez que a força do sistema mestre-explicador possui raízes resistentes e profundas, a proposta de Jacotot pode, no entanto, ser lida como metáfora para várias instâncias da vida, não apenas no que diz respeito à educação propriamente dita. Pensar o indivíduo como intelectualmente capaz, e portanto pensá-lo como um ser livre e desejante pode ser ao menos um modo para encarar a vida (o que não é pouco). Da mesma forma, uma literatura destinada a um leitor que está em formação, que ainda não domina uma língua e que ainda irá passar por inúmeras aventuras para conhecer o mundo, talvez tenha sempre certo cunho educativo. Mas, com Carroll, talvez possamos também vislumbrar a possibilidade de uma obra que não seja condescendente com uma ideia de insuficiência ou incapacidade do infans, do ser em formação; um autor que trata seu público de igual para igual. Ali está Alice, à sombra da sonolência, mas que por si mesma resiste ao tédio e encontra (ou inventa) um túnel a ser descoberto.

\section{Reescritas brasileiras de Carroll: caminhos possíveis}

Neste percurso de articulação da escrita literária de Carroll com as "lições de emancipação intelectual" de Rancière, discutimos também os caminhos tomados em duas reescritas brasileiras de Alice, a de Jorge Furtado e Liziane Kugland (2008) e a de Maria Luiza Borges (2013), buscando entrever que possibilidades de experimentação da linguagem podem ser exploradas em novos textos, os quais em outro sistema literário necessariamente ressignificam Carroll e estabelecem novas relações com o público leitor. Em ambas as reescritas, considera-se que "nenhuma piada tem graça a menos que se possa entendê-la" (Carroll, 2013, p.xii) ou, nas palavras de Furtado e Kugland, "uma piada só tem graça se você a entende" (Carroll, 2008, contracapa); mas, enquanto a tradução de Furtado e Kugland procura não ter que explicar, aproximando o texto do leitor de hoje, a tradução de Maria Luiza Borges parte do pressuposto de que por vezes uma explicação torna-se necessária, por meio de notas. Esses pressupostos distintos relacionam-se ao público-alvo e determinam estratégias tradutórias específicas. Tendo em vista que a obra de Carroll é acessível aos leitores brasileiros por meio de traduções, como as que aqui são abordadas, como poderíamos pensar essa ideia de emancipação intelectual em relação ao leitor de uma obra traduzida? 
Publicada pela Zahar, a tradução de Maria Luiza Borges faz parte de uma edição comentada e ilustrada que contempla Aventuras de Alice no País das Maravilhas e Através do Espelho, além de Introdução e Notas de Martin Gardner. As ilustrações são as originais de John Tenniel. Como aponta Gardner, "muitos personagens e episódios em Alice são resultado direto de trocadilhos e outros jogos linguísticos, e teriam assumido formas completamente diversas se Carroll estivesse escrevendo, digamos, em francês" (Carroll, 2013, p.ix). Se toda reescrita pressupõe certos níveis de adaptação de acordo com a língua e cultura de chegada, no caso de Alice esse aspecto torna-se uma questão central para tradutores e adaptadores. Uma escrita que se desenvolve a partir do que uma palavra inspira ou sugere, que manipula o aspecto formal da linguagem, possivelmente irá demandar alterações mais significativas quando a obra for reescrita em outra língua. A reescrita de Borges, no entanto, evita grandes modificações, caracterizando-se como uma tradução que procura manter uma série de elementos da cultura e língua de origem, ainda que estes sejam distantes da cultura de seu público alvo, demandando assim, eventualmente, algum tipo de pesquisa sobre o texto. $\mathrm{O}$ leitor, todavia, tem acesso aos comentários de Gardner, que contextualizam a escrita de Carroll e, por vezes, explicam situações e aspectos do texto. Como ressalta o comentador,

\begin{abstract}
entre os livros escritos para crianças, não há um que requeira mais explicações que os livros de Alice. Grande parte de sua graça está entretecida com eventos e costumes vitorianos desconhecidos dos leitores americanos [e brasileiros] de hoje, e até dos leitores da Inglaterra. [...] Meu trabalho então não foi fazer pesquisa original mas recolher tudo que encontrasse na literatura existente para tornar os livros de Alice mais prazerosos para leitores contemporâneos. (Carroll, 2013, p.xix)
\end{abstract}

Gardner considera que a obra de Carroll tornou-se de grande interesse para adultos, entre pesquisadores e admiradores do autor, e que, por outro lado, "as crianças hoje sentem-se aturdidas e às vezes apavoradas pela atmosfera de pesadelo do sonho de Alice" (p.viii). Assim, o que garantiria a imortalidade de Carroll seria o interesse do público leitor adulto, e “é apenas para esses adultos que as notas [feitas por Gardner] são dirigidas" (p.viii). Podemos assim considerar que essa edição comentada volta-se para esse público, uma vez que as notas lhe são dirigidas e o texto em inglês apresenta as dificuldades já apontadas. Do mesmo modo, a tradução de Borges, alinhada ao original, mantendo brincadeiras de linguagem e jogos estilísticos, também se volta para o público adulto. Mas se como comenta Gardner, a escrita de Carroll traz obscuridades para crianças de hoje, e uma obra com notas não é um livro que se volte ao público infantil, como então crianças de hoje podem se aventurar pelo mundo de Alice? 
A tradução de Jorge Furtado e Liziane Kugland, publicada pela Objetiva, apresenta-se como um caminho possível para fazer com que o público infantojuvenil conheça as Aventuras de Alice no País das Maravilhas. Os tradutores comentam que a obra é "desde seu nascimento, um livro para crianças. Crianças inglesas do século XIX”, criticando o fato de que, como o livro de Carroll passou a ser apreciado também por adultos, estes "transformaram Alice num livro para adultos, impossível de ser compreendido sem notas de pé de página e longas explicações sobre a língua inglesa ou sobre os hábitos da Oxford vitoriana" (Carroll, 2008, segunda capa). Furtado e Kugland enfatizam que sua tradução é feita para crianças brasileiras do século XXI. A partir desse posicionamento, os tradutores recorrem a uma estratégia que aproxima a obra de seu público alvo, realizando adaptações que tornam o texto inserido na cultura e língua de chegada. A observação acerca das diferenças das reescritas aqui comentadas torna-se relevante também para pensarmos o papel das reescritas na manutenção de cânones, pois são elas que projetam imagens de um escritor, de uma obra, de um período, de um gênero nas mais diversas culturas. Essas imagens existem ao lado das (imagens) originais, mas tendem a alcançar mais pessoas do que as originais correspondentes conseguem (Lefevere, 1992).

Temos nos dois exemplos trazidos aqui uma reescrita que trata Alice de forma mais cerimoniosa, atentando para sua estrangeiridade, a de Maria Luiza Borges, enquanto a de Furtado e Kugland dá as mãos a Alice, trazendo-a para um passeio em nossa cultura. Embora distintas, ambas contribuem para a manutenção do cânone, pois Alice, de Carroll, mantém seu estatuto de "clássico da literatura".

\section{Na toca do coelho: o devir criança}

Alice começa com um poema em que Carroll traz à cena as três irmãs Liddell, Lorina, Alice e Edith, ávidas para que o narrador conte-lhes uma nova história. Cabe à menina Alice antecipar o tom da narrativa que será contada, intimando: “There will be nonsense in it!" (Carroll, 2012, p.3). Abre-se a porta para uma nova dimensão, a do devir criança, da experimentação. Esse "tornar-se criança é ser bem literal; achar tudo tão estranho que nada é surpreendente; é ser impiedoso, selvagem, no entanto ser tão entusiasmado que uma afronta ou tristeza cobre o mundo de sombra. É ser Alice no país das maravilhas"7 (Carroll, 2012, p.246). É entrar na toca do coelho, um túnel que parece não ter fim. Para Alice, o inusitado

\footnotetext{
${ }^{7}$ Tradução nossa do texto de Virginia Woolf sobre Lewis Carroll, inserido ao final da edição.
} 
não é o coelho falar ou estar atrasado, mas sim tirar um relógio do bolso do colete! Isso a inquieta, a desperta, faz com que ela corra atrás e entre na toca, sem pensar em como seria possível sair de lá. Sua curiosidade a move e a põe em risco dentro de um túnel escuro, que acaba se tornando um poço, ou muito fundo ou no qual ela caia muito devagar, pois ali teve tempo para olhar a sua volta e pensar o que aconteceria em seguida (Carroll, 2013, p.9). Assim começa a experiência de Alice por um mundo outro, no qual subverte-se a lógica, despreza-se o tempo linear (tão caro a todos nós) e escancara-se a arbitrariedade da linguagem. Na língua, agora despojada de suas amarras convencionais, Alice experimenta sensações, buscando significados que nunca se apresentam estáveis. Já no primeiro objeto que encontra em sua queda vemos essa passagem para o mundo em que os acontecimentos se dão na e pela linguagem: ela vê um pote, em cujo rótulo se lê "geleia de laranja", mas não havia geleia dentro dele. O "conteúdo" não comparece, o que temos são formas.

Logo, Alice imagina que nessa queda sem fim poderá chegar ao centro da Terra ou quem sabe cair direto através da Terra e chegar do outro lado do mundo, onde tem "gente que anda de cabeça para baixo". A todo tempo Alice busca retomar uma lógica desnecessária. Pode-se perceber uma crítica de Carroll a uma época em que nas escolas os alunos tinham que aprender passivamente uma série de coisas: calcular distâncias, profundidades, saber o nome dos povos. Alice aprende coisas desse tipo para mostrar aos outros o seu saber, e, consciente de que sozinha não poderia exibir seus conhecimentos, procura ao menos praticá-los. Mas as certezas do aprendizado escolar dão lugar a nomes, palavras, que causam estranhamento nessa menina aventureira:

how funny it'll seem to come out among the people that walk with their heads downwards! The antipathies, I think (she was rather glad there was no one listening, this time, as it didn't sound at all the right word). (Carroll, 2012, p.7)

$\mathrm{Na}$ lógica escorregadiça, no embaralhamento da linguagem, as pessoas que vivem "do outro lado do mundo" andam "de cabeça para baixo", e são os...., a palavra escapa, mas surge algo para ocupar esse lugar, são os "antipathies" ("antipatias", como vemos na tradução de Borges). Furtado e Kugland optam nesse ponto por fazer um trocadilho com a palavra "orientais" (o termo que poderia ter sido usado): Alice assim acha que são os "orientados", aqueles que vivem do outro lado do mundo. Mas felizmente não havia ninguém ouvindo, porque a "palavra não parecia estar certa de jeito nenhum" (Carroll, 2008, p.14). E assim Alice segue, questionando, se perguntando, lembrando de sua realidade, com saudades de sua 
gatinha que poderia estar ali com ela e quem sabe pegar algum rato. Mas não tem rato no ar, então poderia pegar um morcego, "que é como um rato", não?

But do cats eat bats, I wonder? And here Alice began to get rather sleepy, and went on saying to herself, in a dreamy sort of way, 'Do cats eat bats? Do cats eat bats? and sometimes 'Do bats eat cats?, for, you see, as she couldn't answer either question, it didn't much matter which way she put it? (Carroll, 2012, p.7-8)

No jogo linguístico, Carroll expõe a arbitrariedade da língua. Haveria uma ordem natural para se realizar a pergunta? De que modo interrogar, quando não se sabe a resposta? “Seria natural a construção 'direta', que dispõe o sujeito antes do verbo e do atributo?" (Rancière, 2013, p.90). Para Alice tanto faz, pois ela não conhece a verdade, não tem a resposta. "A verdade não se diz. Ela é una e a linguagem despedaça, ela é necessária e as línguas são arbitrárias" (p.90). No trecho destacado acima, em que a lógica convencional é torcida, nos resta o experimento com a materialidade dos vocábulos, em que os aspectos sonoro e visual das palavras são trabalhados (cat eat bat/bat eat cat). Como traduzir essa breve passagem, que de certo modo sintetiza a complexidade da tradução literária? O conceito de significância tal como desenvolvido por Mário Laranjeira ${ }^{8}$ nos serve de base para pensar possibilidades tradutórias, pois especialmente

em se tratando de tradução literária e particularmente de tradução de poesia, a tradução não é uma mera troca de significantes com a manutenção do mesmo sentido. A relação significado/significante não é a mesma na prosa científica ou de informação e na poesia. Na poesia essa relação é explodida; o significante não é apenas um veículo, um suporte para o significado, mas adquire certa autonomia. (Faleiros, 2013, p.120)

Desse modo, em uma tradução poética ou literária, "o trabalho do tradutor é ler e (re)produzir sua leitura em outra língua e cultura explorando a poeticidade do texto, sua significância” (Oliveira, 2014, p.85). Com seus jogos linguísticos, com a exploração da forma, a escrita literária de Carroll potencializa esse aspecto da tradução. Nas traduções que aqui utilizamos, Maria Luiza Borges procura manter aquilo que foi dito no texto de Carroll, em detrimento do jogo linguístico (cat eat bat/bat eat cat):

"Mas será que gatos comem morcegos?" e aqui Alice começou a ficar com muito sono, e continuou a dizer para si mesma, como num sonho: "Gatos comem morcegos? Gatos comem morcegos?' e às vezes "Morcegos comem gatos?" pois, como não sabia responder a nenhuma das perguntas, o jeito como as fazia não tinha muita importância. (Carroll, 2013, p.11)

\footnotetext{
${ }^{8}$ Laranjeira, Mário. Poética da tradução. 2 ed. São Paulo: Edusp, 2003.
} 
Já em Furtado e Kugland, aquilo que é dito acaba sendo modificado, enquanto o que se busca recriar é a brincadeira sonora e visual. Podemos associar tal trabalho à perspectiva de Haroldo de Campos ao propor "uma poética tradutória que enfatiza a recriação dos aspectos formais (sonoros e imagéticos) do texto estrangeiro, com objetivo de reconstituir a informação estética (em oposição à meramente semântica)" (Martins, 2005, p. 136), como vemos a seguir:

"Mas será que gato come morcego?" E então Alice começou a ficar com bastante sono e continuou falando sozinha, como num sonho: "Morcego é como rato e gato come rato... Ga-to-co-me-ra-to...Gato come rato?", e às vezes, "Ra-to-co-me-ga-to?" Sabe como é, já que ela não conseguia responder nenhuma das perguntas, não importava muito a ordem das palavras. (Carroll, 2008, p.15)

Como vemos, na elaboração de uma reescrita há caminhos possíveis para trabalhar a significância de uma obra literária, os quais irão variar de acordo com os objetivos de cada uma.

Após a queda, continuando seu percurso nesse mundo subterrâneo, Alice se depara com portas fechadas, que não sabe como abrir. Encontra uma chave minúscula mas, que azar!, "ou as fechaduras eram muito grandes ou a chave era muito pequena" (Carroll, 2008, p.16). O desejo de falar, de explicar, esgarça os dizeres, que se redobram, redundam, tautológicos e irônicos. Somente em uma segunda volta no salão é que ela encontra uma porta que de tão pequena serve na chave, e assim ela vê “o jardim mais adorável que você jamais viu” (p.16), mas não consegue cruzar a porta, pois seu tamanho não permite. Alice então deseja encolher para chegar ao jardim. A partir desse momento, começam suas experiências de alteração de tamanho, seu devir corporal, que a angustia, pois, de início, ela não tem controle sobre o quanto vai crescer ou diminuir. Na primeira vez que encolhe, ao beber o conteúdo da garrafa BEBA-ME, chega a ficar com apenas 25 centímetros e a pensar que poderia sumir tal como a chama de uma vela que se apaga. "E tentou imaginar como é a chama de uma vela depois que a vela se apaga, pois não conseguia se lembrar de jamais ter visto tal coisa" (Carroll, 2013, p.14). A menina, que jogava croqué disputando consigo mesma, gostava de fingir ser duas pessoas, mas em tamanho tão reduzido mal sobrava algo de si para ser uma pessoa apresentável. Ao rever o coelho branco, após comer o bolo em que estava escrito COMA-ME e ter ficado enorme, Alice percebe como tudo está tão esquisito. Teria ela sido trocada durante a noite? Era ainda a mesma pessoa quando acordou? Pensando bem ela tinha se sentido um pouco diferente. Mas se não fosse a mesma pessoa, quem afinal de contas seria ela? (Carroll, 
2012, p.14). Carroll explora a lógica em seus limites, dos estranhos acontecimentos à dúvida existencial.

Tentando ver se era a mesma, se ainda sabia as mesmas coisas, Alice procura ver se recordava aquilo que tinha aprendido na escola. Seus conhecimentos de matemática, de geografia, de tudo o que tinha aprendido seriam a garantia de que ela era ela mesma. Mas tudo lhe parece confuso. Realmente deve ter sido trocada pela Mabel! Tenta então recitar, mas "as palavras não vieram como costumavam” (Carroll, 2013, p. 19):

How doth the little crocodile Improve his shining tail And pour the waters of the Nile On every golden scale!

How cheerfully he seems to grin, How neatly spreads his claws, And welcomes little fishes in, With gently smiling jaws! (Carroll, 2012, p.15)

Em suas notas, Gardner comenta que a maioria dos poemas nos livros de Alice "são paródias de poemas ou canções populares muito conhecidos pelos leitores contemporâneos de Carroll" (Carroll, 2013, p.264). No entanto, enquanto os originais caíram no esquecimento, as paródias permanecem vivas na obra do autor inglês, bem como em suas reescritas, como vemos a seguir na tradução de Borges:

Como pode o crocodilo

Fazer sua cauda luzir

Borrifando a água do Nilo

Que dourada vem cair?

Sorriso largo, vai nadando,

E de manso, enquanto nada,

Os peixinhos vai papando

Co'a bocarra escancarada!

(Carroll, 2013, p.19)

Trata-se de uma paródia de um poema de Isaac Watts (1674-1748), “Against Idleness and Mischief”, no qual o poeta trazia o tema da abelha que com habilidade constrói seu alvéolo e prepara seu alimento, sendo assim uma inspiração para ele. Em oposição à abelha ágil e trabalhadora, Carroll utiliza a imagem do crocodilo que sorrateiramente vai devorando suas presas. É claro que o público leitor de hoje só poderá perceber a paródia, e entender porque Alice diz que "as palavras não vieram do mesmo jeito que eram antes" (Carroll, 2008, 
p.25), ao ler a nota explicativa de Gardner. Mais uma vez aqui observamos os caminhos distintos relativos às estratégias tradutórias. Furtado e Kugland optam por fazer uma paródia que não necessite de explicação. Para isso, introduzem interpolações no texto, utilizando um poeminha popular no Brasil (batatinha quando nasce) e o embaralham inserindo situações pelas quais Alice acabou de passar:

\author{
Batatinha quando nasce \\ Come bolo de montão \\ Menininha quando cresce \\ Fica presa no salão. \\ (Carroll, 2008, p.25)
}

Dessa confusão linguística, ela conclui que só pode ter sido trocada! E Alice continua em sua tentativa desesperada de entrar no jardim, aumentando e diminuindo de tamanho. Acaba chorando tanto que começa a nadar no lago de suas próprias lágrimas. No lago, encontra um rato (que de tão grande, para a diminuta menina, parecia uma morsa ou um hipopótamo). Ela que nunca havia falado com um rato lembra-se de ter visto na gramática latina de seu irmão: "Um camundongo, de um camundongo, para um camundongo, um camundongo... ó camundongo" (Carroll, 2013, p.21). Alice faz assim o inesperado uso do vocativo e interpela o rato: "Ó camundongo, sabe como se faz para sair desta lagoa? Estou muito cansada de ficar nadando para todo lado, ó camundongo!” (p.21). Como não recebe resposta, Alice pensa:

'Talvez não entenda inglês' [...]. 'Aposto que é um camundongo francês, que veio com Guilherme, o Conquistador'. (Pois, com todo seu conhecimento de história, Alice não tinha lá uma ideia muito clara de há quanto tempo qualquer coisa tinha acontecido.) Assim, recomeçou: 'Où est ma chatte?' que era a primeira frase do seu livro de francês. (Carroll, 2013, p. 21)

No original, temos (Carroll, 2012, p.18):

'Perhaps it doesn't understand English' [...]. 'I daresay it's a French mouse, come over with William the Conqueror.'(For, with all her knowledge of history, Alice had no very clear notion how long ago anything had happened.) So she began again: 'Où est ma chatte?', which was the first sentence in her French lesson-book.

Notamos que a tradução de Maria Luiza Borges mantém o que é dito no original, marcando o caráter estrangeiro da personagem que fala "inglês", embora estejamos lendo tudo o que é dito por ela em nosso idioma, o português. Na tradução de Furtado e Kugland temos a adaptação: 
'Talvez ele não entenda português' [...]. 'Eu arriscaria dizer que ele é um rato espanhol e chegou aqui à América com Cristóvão Colombo' (É que, mesmo com todo o seu conhecimento de história, Alice não tinha uma noção muito clara de há quanto tempo as coisas tinham acontecido. Então, ela começou de novo: - Donde está mi gato? - que era a primeira frase de seu livro de espanhol. (Carroll, 2008, p.28).

A personagem e seu contexto são trazidos para a cultura brasileira, e o estrangeiro em vez de ser o conquistador francês passa então a ser o espanhol. Esse tipo de adaptação pode ser visto em outros momentos na tradução de Furtado e Kugland. Sempre que há um momento de referência a um contexto histórico, relativo à vida de Alice, temos algum tipo de adaptação seja no campo formal seja naquilo que é propriamente dito, ou ainda uma mistura entre esses dois campos. Por exemplo, quando Alice e os bichos que encontrara ficam encharcados, o rato propõe algo para deixar todos bem secos e, dizendo "esta é a coisa mais seca" que conhece, se põe a contar:

Guilherme, o conquistador, cuja causa era apoiada pelo papa, logo se rendeu aos ingleses, que queriam ser líderes, e andavam ultimamente muito acostumados com usurpação e conquista. Edwin e Morcar, condes da Mércia e da Nortúmbria...”. (Carroll, 2013, p.23)

A mesma narrativa está presente no original:

This is the driest thing I know. [...] William the Conqueror, whose cause was favoured by the pope, was soon submitted to by the English, who wanted leaders, and had been of late much accustomed to usurpation and conquest. Edwin and Morcar, the earls of Mercia and Northumbria. (Carroll, 2012, p.21)

Nas notas de Gardner, presentes na edição traduzida por Maria Luiza Borges, temos a explicação para o motivo da existência de tal história "tão seca"; a passagem é "uma citação real do livro de Havilland Chepmell, Short Course of History (1862), p.143-4. [...] O livro de Chepmell era um dos manuais que as meninas Liddell estudavam" (Carroll, 2013, p.267). Já Furtado e Kugland, consonantes com seus objetivos, modificam a história contada pelo rato, inserindo na narrativa um trecho do poema "Navio negreiro" de Castro Alves. Trazem assim um poeta brasileiro do século XIX, portanto contemporâneo a Carroll. Os tradutores fazem ainda uma transposição em relação à metáfora da "história seca". Enquanto no original "a secura" refere-se mais ao gênero da obra e ao estilo da escrita, o trecho do poema trazido por Furtado e Kugland contém elementos semânticos que remetem à seca. A tradução aqui pode ser considerada um "canto paralelo", tal como preconizado por Haroldo de Campos, um diálogo não apenas com a voz do original, mas com outras vozes textuais; uma recriação que 
funde tradições literárias, desmistificando assim qualquer pressuposto de superioridade do “original”, do autor ou da cultura fonte (Martins, 2005, p. 135). Assim, mais importante do que o poema em si parece ser a utilização das palavras contidas no mesmo (Carroll, 2008, p.34):

\footnotetext{
Depois, o areal extenso

Depois, o oceano de pó

Depois no horizonte imenso

Desertos...desertos só...

E a fome, o cansaço, a sede,

Ai quanto infeliz que cede...
}

\section{Considerações finais}

Muitas outras considerações podem ser feitas acerca dos inúmeros jogos linguísticos, das distorções lógicas, das manipulações realizadas por Carroll e das soluções vistas nas traduções aqui comentadas, mas, dado o escopo deste artigo, tratamos apenas de alguns exemplos significativos, que mostram o trabalho de Carroll na elaboração de sua escrita literária sem receio de se lançar no risco de não saber aonde chegar. Em uma época em que a literatura tinha um forte caráter moral, ou de formação, imprimir um tratamento a uma peça literária como Carroll faz em Alice parece ser aventar a possibilidade da arte pela arte, com uma existência independente de um projeto educativo, moralizante ou com alguma outra finalidade. É nesse sentido que podemos fazer a aproximação de Alice com $O$ mestre ignorante.

Quanto às reescritas, embora distintas em seus propósitos e soluções apresentadas, ambas dignificam a insubmissa Alice, pois não são condescendentes com seus leitores. São (re)escritas ousadas, que não simplificam a obra para explicá-la. Seguindo caminhos distintos, propõem ao leitor uma experiência literária, na qual o estético, o jogo com a linguagem, emerge do texto. A tradução de Maria Luiza Borges, em edição comentada por Martin Gardner, encoraja o leitor brasileiro a adentrar no contexto da escrita de Carroll, em uma reescrita que não busca aproximar a obra da cultura meta. Embora possa gerar certa relação de estranhamento do leitor para com o texto, tal estratégia possibilita um contato mais estreito com o contexto do autor. Por outro lado, a tradução de Furtado e Kugland, que realiza maiores alterações visando o público infantil, não obstante as aproximações com a cultura alvo, não banaliza a obra. Ao contrário, realiza um trabalho primoroso, buscando a significância do texto literário. Vemos que é possível trazer a literatura do autor inglês do século XIX para o

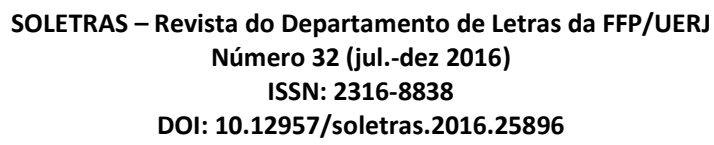




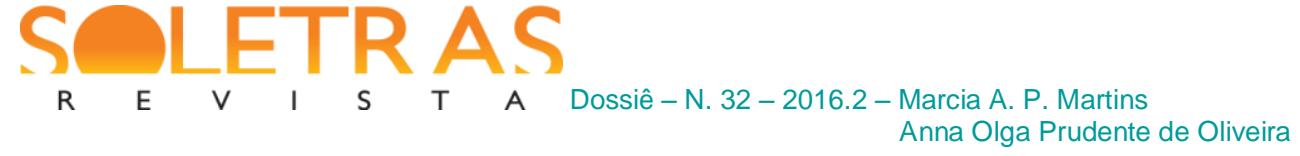

Brasil do século XXI sem cair na lógica do sistema explicador, que inferioriza o outro. Em vez disso, pode-se realizar uma reescrita que assume sua condição de uma leitura da obra, uma leitura dentre outras possíveis, mas que contém toda a complexidade de uma escrita literária, de uma obra poética.

\section{Referências}

CARROLL, Lewis. Alice: Aventuras de Alice no País das Maravilhas; \& Através do Espelho. Tradução: Maria Luiza X. de A. Borges. Rio de Janeiro: Zahar, 2013. Alice's Adventures In Wonderland And Through The Looking-Glass And What Alice Found There. London: Penguin, 2012.

Aventuras de Alice no País das Maravilhas. Tradução: Jorge Furtado e Liziane Kugland. Rio de Janeiro: Objetiva, 2008.

DELEUZE, Gilles. "Lewis Carroll"; "O que as crianças dizem"; "Gaguejou...". In: Crítica e clínica. Trad. Peter Paul Pelbart. São Paulo: Editora 34, 2011.

FALEIROS, Álvaro. "Entrevista - Mário Laranjeira”. In: . (org.). Mário Laranjeira: poeta da tradução. São Paulo: Dobra, 2013. p.117-126.

KOHAN, Walter. Infância, estrangeiridade e ignorância. Ensaios de filosofia e educação. Belo Horizonte: Autêntica, 2007.

LARROSA, Jorge. "O enigma da infância". In: Pedagogia Profana: danças, piruetas e mascaradas. Tradução: Alfredo Veiga-Neto. 4 ed. Belo Horizonte: Autêntica, 2004. p.183-198.

LEFEVERE, André. Translation, Rewriting, and the Manipulation of Literary Fame. London: Routledge, 1992.

MARTINS, Marcia A. P. “Os Estudos da Tradução no Brasil”. In: DINIZ, Júlio C. V. (org.). Diálogos Ibero-americanos. Rio de Janeiro: Galo Branco, 2005. p. 122-138.

MORAIS, Flávia Costa. Literatura vitoriana e educação moralizante. Campinas, SP: Alínea, 2004. 
O’CONNELL, Eithne. “Translating for Children”. In: LATHEY, Gillian. The Translation of Children's Literature: A Reader. UK: Multilingualmatters, 2006. p. 15-24.

OLIVEIRA, Anna Olga Prudente de. Chapeuzinho Vermelho: marcas ideológicas e poetológicas de suas escritas e reescritas. 2014. 130 f. Dissertação (Mestrado em Letras/Estudos da Linguagem) - PUC-Rio, Rio de Janeiro.

PIMENTEL, Figueiredo. Contos da Carochinha. Rio de Janeiro: Quaresma \& CA Livreiros Editores, [1911].

RANCIÈRE, Jacques. $O$ mestre ignorante. Cinco lições sobre a emancipação intelectual. Tradução: Lílian do Valle. 3 ed. Belo Horizonte: Autêntica, 2013.

ROSA, João Guimarães. Grande Sertão: Veredas. Rio de Janeiro: Nova Aguilar, 1994.

SHAVIT, Zohar. "The Concept of Childhood and Children's Folktales: Test Case - 'Little Red Riding Hood'”. In: TATAR, Maria (ed.). The Classic Fairy Tales. New York, London: Norton, 1999. p. 317-332.

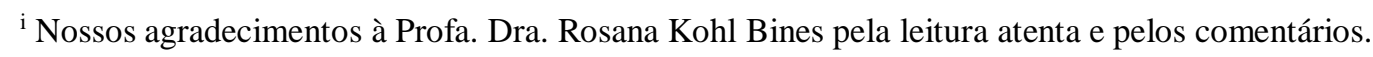

\title{
Alice and The Ignorant Schoolmaster: relations between the literary work and the educational experience
}

\begin{abstract}
The purpose of this article is to analyze Lewis Carroll's Alice Adventures in Wonderland drawing upon Jacques Rancière's reflections in The Ignorant Schoolmaster (Le maître ignorant, 1987). Considering that Alice has become part of the children's literature canon, we point out aspects of Carroll's writing that sharply distinguishes it from books with an educational and/or moralizing bias. Without resorting to a linear narrative, Carroll values the child's perspective, experimenting with language. This experimentation and the absence of a teleological or pedagogical purpose invite an analogy with Rancière's text, in which the author breaks with the traditional teacher-student hierarchy and presents instead a radical proposal of intellectual emancipation. Articulating Carroll's literary writing and Rancière's "lessons on intellectual emancipation," two different rewritings of Alice in Brazilian Portuguese are discussed: by Jorge Furtado and Liziane Kugland's (2008) and by Maria Luiza Borges (2013).
\end{abstract}

Keywords: Children's literature. Translation and adaptation. Intellectual emancipation. Lewis Carroll. Jacques Rancière.

Recebido em: 07 de outubro de 2016.

Aprovado em: 03 de janeiro de 2017. 